\title{
Desinfecção à base de radiação ultravioleta-c: um estudo bibliométrico no contexto internacional
}

\author{
Disinfection based on ultraviolet-c radiation: a bibliometric study in the international context \\ Desinfección basada en la radiación ultravioleta-c: un estudio bibliométrico en el contexto \\ internacional
}

Recebido: 08/01/2021 | Revisado: 10/01/2021 | Aceito: 20/01/2021 | Publicado: 24/01/2021

Jackeline Franco Couto

ORCID: https://orcid.org/0000-0002-7720-0102 Universidade Federal do Estado do Rio de Janeiro, Brasil

E-mail: jack.enfa@hotmail.com

Maguel Souza da Silva

ORCID: https://orcid.org/0000-0003-3142-9777 Universidade Federal do Estado do Rio de Janeiro, Brasil E-Mail: maguel.unirio@gmail.com

Wiliam César Alves Machado

ORCID: https://orcid.org/0000-0002-4325-7143 Universidade Federal do Estado do Rio de Janeiro, Brasil E-Mail: wily.machado@gmail.com

Maria Antonieta Rúbio Tyrrel

ORCID: https://orcid.org/0000-0002-1885-6865

Universidade Federal do Rio de Janeiro, Brasil E-mail: tyrrel12004@hotmail.com

Fellipe Franco Couto

ORCID: https://orcid.org/0000-0003-4338-3673

Minerva Schools at KGI, Estados Unidos

E-mail: fellipefrancocoutom@gmail.com

Márcia Adriana Silva Nunes

ORCID: https://orcid.org/0000-0003-4750-8357

Laboratório Central de Saúde Pública Noel Nutels, Brasil

E-mail: nunes.bio@gmail.com

Nébia Maria Almeida de Figueiredo

ORCID: https://orcid.org/0000-0003-0880-687X

Universidade Federal do Estado do Rio de Janeiro, Brasil

E-Mail: nebia43@gmail.com.br

\begin{abstract}
Resumo
Objetivo: Identificar e analisar a produção científica sobre o uso de raios ultravioleta-c para fins de desinfecção, descontaminação e esterilização, publicada em artigos de periódicos no período de 2014 a 2018. Métodos: Pesquisa exploratória com abordagem quali-quantitativa, realizada na base de dados Web of Science. Resultados: Foram recuperados 230 artigos científicos, o ano de 2018 apresentou o maior número de artigos (29\%). Estados Unidos da América (28\%) foi o maior país gerador de publicações e o idioma inglês $(98 \%)$ o mais recorrente. O mapeamento da distribuição de artigos por periódico, apontou que $16(15 \%)$ revistas concentraram a publicação de $99(43 \%)$ artigos. A averiguação das aplicações da radiação ultravioleta-c apontou a predominância em alimentos (32\%) e as bactérias (53\%) dentro do levantamento dos microrganismos alvos. Conclusão: As publicações sobre o uso da tecnologia apontam sua diversidade de aplicação nos diferentes segmentos, tais como indústria de alimentos e ambientes hospitalares.
\end{abstract}

Palavras-chave: Raios ultravioleta; Desinfecção; Descontaminação; Esterilização; Bibliometria.

\begin{abstract}
Objective: To identify and analyze scientific production on the use of ultraviolet-C rays for disinfection, decontamination and sterilization, to publish journal articles from 2014 to 2018. Method: Exploratory research with a qualitative and quantitative approach. A survey was conducted in the Web of Science database. Results: 230 scientific articles were retrieved, 2018 had the largest number of articles (29\%). United States of America (28\%) is the country that generates the most publications making the English language (98\%) the most recurrent. The mapping of the distribution of periodical articles showed that $16(15 \%)$ journals concentrated on the publication of $99(43 \%)$ articles. The average evaluation of the applications of ultraviolet-C radiation pointed to the predominance of the use of technology in food (32\%) and bacteria (53\%) in relation to the survey of microorganisms. Conclusion: Publications
\end{abstract}


on the use of ultraviolet- $\mathrm{C}$ technology point to its diversity of application, being used in different filters, such as the food industry and hospital environments.

Keywords: Ultraviolet rays; Disinfection; Decontamination; Sterilization; Bibliometrics.

\section{Resumen}

Objetivo: identificar y analizar la producción científica sobre el uso de rayos ultravioleta-C para la desinfección, descontaminación y esterilización, publicar artículos de revistas de 2014 a 2018. Métodos: investigación exploratoria con un enfoque cualitativo y cuantitativo. Se realizó una encuesta en la base de datos de Web of Science. Resultados: se recuperaron 230 artículos científicos, 2018 tuvo el mayor número de artículos (29\%). Estados Unidos de América $(28 \%)$ es el país que genera más publicaciones, lo que hace que el idioma inglés $(98 \%)$ sea el más recurrente. El mapeo de la distribución de artículos periódicos mostró que 16 (15\%) revistas se concentraron en la publicación de 99 (43\%) artículos. La evaluación promedio de las aplicaciones de la radiación ultravioleta-C señaló el predominio del uso de tecnología en alimentos (32\%) y bacterias (53\%) en relación con el estudio de microorganismos. Conclusión: las publicaciones sobre el uso de la tecnología ultravioleta-C apuntan a su diversidad de aplicaciones, que se utilizan en diferentes filtros, como la industria alimentaria y los entornos hospitalarios.

Palabras clave: Rayos ultravioleta; Desinfección; Descontaminación; Esterilización; Bibliometría.

\section{Introdução}

A luz ultravioleta (UV) está entre as tecnologias investigadas com intensidade no mundo como alternativa aos procedimentos de desinfecção nos diversos tipos de ambientes e superfícies.

Normalmente, o comprimento de onda para processamento da radiação ultravioleta (UV) varia entre 100 e 400 nanômetros (nm). Este intervalo pode ser subdividido em Ultravioleta-A (UV-A) (315-400 nm), geralmente responsável por alterações na pele humana, denominado bronzeamento; Ultravioleta-B (UV-B) (280-315 nm), que pode causar queimaduras e eventualmente levar a cancro de pele; Ultravioleta-C (UV-C) (200-280 nm), denominado faixa germicida, uma vez que efetivamente inativa bactérias e vírus (Choudhary \& Bandla, 2012).

O método de desinfecção por irradiação ultravioleta (UV) vem sendo frequentemente utilizado para substituição ou complementação de outros métodos como a pasteurização e desinfecção por cloro e seus derivados em alimentos como sucos de frutas (Liu, Huang, \& Chen , 2015). Em alimentos sólidos é comumente utilizado para tratar a sua superfície (Araque, et al., 2018).

A desinfecção é o processo físico ou químico que destrói todos os microrganismos patogênicos de objetos inanimados e superfícies, com exceção de esporos bacterianos (Coordenação de Controle de Infecção, 1994). A radiação Ultravioleta-C é um tipo de desinfecção que ocorre por meio físico.

Pesquisas comprovam a eficácia desta tecnologia no controle de infecções hospitalares mostrando que o espectro específico de irradiação ultravioleta mata bactérias resistentes aos medicamentos que residem dentro de um ambiente hospitalar, como puxadores de portas, mesas de cabeceira e demais superfícies. Desta forma, esta tecnologia é uma arma poderosa para diminuir o tempo de internação e salvar vidas (Sachs, Medeiros, \& Rodrigues, 2015).

O raio UV-C passa através das paredes celulares de bactérias, vírus e esporos de bactérias, sendo absorvido pelo DNA, RNA e proteínas resultando na eliminação de vírus, fungos e bactérias que poderiam ameaçar a saúde (Clímaco, et al., 2018).

Equipamentos à base de radiação ultravioleta-c são utilizados e operam há mais de uma década nos países desenvolvidos, em especial, Estados Unidos da América, Dinamarca, Canadá, Alemanha, China, e proporcionando resultados positivos sobre a utilização da tecnologia para desinfecção nos alimentos líquidos e sólidos, nos ambientes intra e extra hospitalares, na água, em superfícies, nas algas, nas plantas, dentre outros.

No Brasil, estudo realizado em 2018, na Escola de veterinária da Universidade Federal de Minas Gerais, teve como objetivo avaliar o efeito de diferentes procedimentos de desinfecção como alternativas à fumigação com formaldeído na carga microbiana da casca de ovo e concluiu que a exposição à luz Ultravioleta é eficaz na redução da carga microbiana em cascas 
de ovos de criadores, sem afetar sua qualidade, e pode ser considerada uma alternativa à desinfecção por formaldeído (Clímaco, et al., 2018).

Pesquisa publicada em 2018, investigou, estudou os efeitos microbianos e de qualidade dos tratamentos com luz UVC e UV pulsada sobre a Listeria monocytógenes, realizados sob condições relevantes da indústria em salmão cru e defumado a frio e evidenciou que os métodos Ultravioletas são tratamentos de descontaminação de superfície que podem ser usados em várias etapas no processamento contínuo de matérias-primas, peixes processados e produtos finais, além de serem fáceis de implementar, seguros de aplicar e não exigirem aumento da carga de trabalho (Holck, Liland, M, \& E, 2018).

De acordo com estudo realizado em 2018, a implementação da tecnologia UV-C foi associada à redução de $44 \%$ na incidência de infecções virais entre pacientes pediátricos no Hospital Infantil de St. Mary's, uma instalação de 97 leitos localizada em Bayside, Nova York. O UV-C foi incluído como um complemento aos protocolos de limpeza padrão durante um período de 12 meses; nenhuma outra nova intervenção foi introduzida durante esse período. Os resultados sugerem que a tecnologia UV-C é um componente potencialmente importante para eliminar no meio ambiente as infecções virais (Pavia, Simpser, Becker, Mainquist, \& Velez, 2018).

Tendo em vista a relevância da tecnologia de raios UV-C como método físico de controle microbiano, bem como sua diversidade de aplicação, considera-se pertinente identificar o panorama da produção científica sobre a utilização de raios UVC para fins de desinfecção, descontaminação e esterilizações

\section{Metodologia}

A presente pesquisa possui caráter exploratório abordagem quali-quantitativa. Utilizou-se como técnica a bibliometria para analisar a produção científica correlacionada à utilização de tecnologia Ultravioleta-C para fins de desinfecção, descontaminação e esterilização, selecionando-se apenas artigos de periódicos publicados entre 2014 a 2018.

Os métodos qualitativos são aqueles nos quais é importante a interpretação por parte do pesquisador com suas opiniões sobre o fenômeno em estudo (Pereira, Shitsuka, Parreira \& Shitsuka, 2018)

Nos métodos quantitativos, faz-se a coleta de dados quantitativos ou numéricos por meio do uso de medições de grandezas e obtém-se por meio da metrologia, números com suas respectivas unidades. Estes métodos geram conjuntos ou massas de dados que podem ser analisados por meio de técnicas matemáticas como é o caso das porcentagens, estatísticas e probabilidades, métodos numéricos, métodos analíticos e geração de equações e/ou fórmulas matemáticas aplicáveis a algum processo (Pereira, Shitsuka, Parreira \& Shitsuka, 2018)

A pesquisa foi realizada na base de dados Web of Science (WoS), durante o mês de novembro de 2019. A base de dados Wos foi escolhida pelo fato de fornecer uma cobertura de aproximadamente 12.000 periódicos, permitindo acesso a referências e resumos em diversas áreas do conhecimento, com disponibilidade de acesso desde 1945 até o presente. Ademais, a Wos disponibiliza uma ferramenta de análise de resultados de pesquisa, o que facilita a realização das análises bibliométricas. A pesquisa foi iniciada a partir da formulação da seguinte questão: qual o panorama mundial da produção de artigos sobre o uso de tecnologia uv-c para fins de desinfecção, descontaminação e esterilização.

Para a realização da análise bibliométrica, selecionou-se os seguintes indicadores de produção científica: ano de publicação, países, idiomas, periódicos e organizações. Incluí-se também a identificação da aplicação geral e específica da radiação ultravioleta-c, bem como os microrganismos alvo da tecnologia de raios ultravioleta-C.

A identificação das aplicações da tecnologia de raios ultravioleta-c e dos microorganismos alvo foi feita por meio da leitura do título e resumo de todos os artigos recuperados. 
A partir da formulação da questão da pesquisa, foram identificados os termos representativos do assunto abordado no presente estudo. Os termos identificados foram pesquisados no DeCS $^{1}$ (Descritores em Ciências da Saúde) para fins de mapeamento do vocabulário controlado e dos sinonimos dos descritores.

$\mathrm{Na}$ base de dados Wos foi selecionada a opção 'Pesquisa avançada', utilizando o rótulo de campo $\mathrm{TS}^{2}$ (Tópico), estipulando o intervalo temporal de 2014 até 2018. Foram utilizados os operadores booleanos OR e AND para combinar as expressões de busca. $\mathrm{O}$ caracter asterisco (*) foi aplicado para permitir a busca pelo radical das palavras. Desta forma, na busca realizada para este estudo, utilizou-se a seguinte estratégia: TS= (ray* OR light OR *radiation) AND TS= ("Ultraviolet-C" OR "UV-C") AND TS=(disinfection* OR sterilization* OR *contamination*).

O resultado da busca foi baixado no formato de arquivo de texto e, em seguida, importado para o MS Excel para mineração de texto e geração de gráficos.

\section{Resultados e Discussão}

Por meio da aplicação da estratégia de busca descrita anteriormente, foram recuperados 230 artigos relacionados à desinfecção, descontaminação e esterilização à base de radiação ultravioleta-c, publicados em periódicos científicos no período de 2014 a 2018.

Em relação ao número de publicações no período de 2014 a 2018, observou-se o aumento no número de artigos relacionados ao uso da radiação ultravioleta-c para fins de desinfecção, descontaminação e esterilização. No ano de 2014 foram identificados 35 artigos (15\%), tendo havido um inexpressivo decréscimo em 2015, com 31 artigos (13\%) publicados. Em 2016, 57 artigos (25\%) e no ano de 2017, 41 artigos (18\%). Apesar de haver uma queda no número de publicações em 2017 (18\%) se comparado ao ano de 2016 (25\%), nota-se que em 2018 o quantitativo de publicações foi intensificado, tendo sido contabilizados 66 artigos (29\%), demonstrando que o interesse pelo tema cresce mundialmente.

O levantamento das publicações por país permitiu identificar os 10 países com mais registros na wos (Tabela 1). Observou-se que os Estados Unidos da América (65), Espanha (27) e china (21), foram os países que mais publicam sobre o assunto, seguidos pela Alemanha (17), que ocupou o quarto posição no ranking. O expressivo número de publicações dos Estados Unidos da América, provavelmente deve-se à posição de economia dominante que o país assumiu com o fim da segunda guerra, exportando elementos culturais, fenômeno denominado globalização.

\footnotetext{
† O DeCS é um vocabulário estruturado, dinâmico e multilíngue, criado pelo Centro Latino-Americano e do Caribe de Informação em Ciências da Saúde (BIREME) para padronizar a indexação de materiais bibliográficos e ser usado na pesquisa e recuperação de assuntos da literatura científica em diversas fontes de informação na área de Ciências da Saúde.
}

$\$$ O rótulo de campo TS (Tópico) permite a busca pelos termos no título, no resumo, nas palavras-chave do autor e nos Keywords Plus de cada artigo. 
Tabela 1. Ranking dos 10 países que mais publicam sobre o assunto. Rio de Janeiro, RJ, Brasil, 2020.

\begin{tabular}{|lcc|}
\hline País & Registros & $\%$ of 230 \\
\hline Estados Unidos da América & 65 & 28.261 \\
\hline Espanha & 27 & 11.739 \\
\hline China & 21 & 9.130 \\
\hline Alemanha & 17 & 7.391 \\
\hline Canadá & 15 & 6.522 \\
\hline Itália & 15 & 6.522 \\
\hline Coréia do Sul & 13 & 5.652 \\
\hline Brasil & 11 & 4.783 \\
\hline França & 9 & 3.913 \\
\hline Japão & 8 & 3.478 \\
\hline
\end{tabular}

Fonte: Autores, a partir de dados coletados na WOS.

No que se refere à produção de artigos por idioma, constatou-se a predominância de publicação em Inglês, com 225 registros (98\%) encontrados, seguido do idioma Espanhol, com quatro publicações $(1,5 \%)$ e do Checo, com uma publicação $(0,5 \%)$. A preponderância de publicação na língua inglesa é um indicador de evolução de um tema de pesquisa, visto que é um dos pré-requisitos para publicação em periódicos estrangeiros, em diversos segmentos de pesquisa.

Os 230 artigos recuperados na WOS estão distribuídos em 113 periódicos. Ao mapear a distribuição do número de artigos por periódico, constatou-se que 16 (15\%) revistas publicaram até quatro artigos, sendo responsáveis por 99 (43\%) artigos publicados. No grupo dos 16 periódicos que mais publicaram sobre o tema constam os seguintes títulos: Innovative Food Science \& Emerging Technologies (10), American Journal Of Infection Control (11) e Food Control (10) apresentam o maior número de publicações. Na sequência aparecem: Food And Bioprocess Technology (oito); Infection Control And Hospital Epidemiology (oito); Water Research (sete); Science of The Total Environment (seis); Journal of Hazardous Materials (cinco); Applied And Environmental Microbiology (quatro); Environmental Science And Pollution Research (quatro); Food Microbiology (quatro); International Journal of Food Microbiology (quatro); Journal of Food Processing And Preservation (quatro); Food Science And Technology-Lebensmittel-Wissenschaft \& Technologie (quatro); Photochemistry And Photobiology (quatro); e Postharvest Biology And Technology (quatro). Foi realizar a pesquisa na base Ulrichsweb ${ }^{\S}$ para rastrear os principais temas cobertos pelas 16 revistas, tendo-se identificadas as seguintes áreas temáticas: Ciência e Tecnologia de Alimentos (cinco); Ciências Ambientais (quatro); Biologia/Microbiologia (dois); Biologia/Biotecnologia (dois); Doenças infecciosas (dois) e Bioquímica e Biologia Molecular (um).

O Quadro 1 apresenta as organizações que mais publicaram sobre o assunto no período de 2014 a 2018 , de modo a sintetizar as informações sobre as aplicações da tecnologia de raios UVC e os microrganismos alvo abordados nos artigos por elas publicados. 
Quadro 1. Organizações que mais publicaram sobre o assunto no período de 2014 a 2018. Rio de Janeiro, RJ, Brasil, 2020.

\begin{tabular}{|c|c|c|c|}
\hline Organização & Registros & Aplicações da tecnologia UVC & Microrganismo alvo \\
\hline $\begin{array}{l}\text { Case Western } \\
\text { Reserve University } \\
\text { - (EUA) }\end{array}$ & 8 & $\begin{array}{l}\text { Equipamentos hospitalares (3); } \\
\text { superfícies } \quad-\quad \text { ambiente } \\
\text { hospitalar (2); tela de } \\
\text { computador (2); superfícies - } \\
\text { ambiente extra hospitalar (1) }\end{array}$ & $\begin{array}{l}\text { Staphylococcus aureus resistente à meticilina } \\
\text { (MRSA) e esporos de Clostridium difficile (3); } \\
\text { Candida auris e MRSA (1); Escherichia coli e } \\
\text { e esporos de Clostridium difficile (1); } \\
\text { Staphylococcus aureus resistente à meticilina } \\
\text { (MRSA) (1); Esporos de Clostridium difficile, } \\
\text { Staphylococcus aureus resistente à meticilina } \\
\text { (MRSA) e Enterococcus resistente à } \\
\text { vancomicina -VRE-(2). }\end{array}$ \\
\hline $\begin{array}{l}\text { Louis Stokes } \\
\text { Cleveland Veterans } \\
\text { Affairs Medical } \\
\text { Center - (EUA) }\end{array}$ & 8 & $\begin{array}{l}\text { Equipamentos hospitalares (3); } \\
\text { superfícies } \quad-\quad \text { ambiente } \\
\text { hospitalar (2); tela de } \\
\text { computador (2); superfícies - } \\
\text { ambiente extra hospitalar (1) }\end{array}$ & $\begin{array}{l}\text { Staphylococcus aureus resistente à meticilina } \\
\text { (MRSA) e esporos de Clostridium difficile (3); } \\
\text { Candida auris e MRSA (1); Escherichia coli e } \\
\text { e esporos de Clostridium difficile (1); } \\
\text { Staphylococcus aureus resistente à meticilina } \\
\text { (MRSA) (1); Esporos de Clostridium difficile, } \\
\text { Staphylococcus aureus resistente à meticilina } \\
\text { (MRSA) e Enterococcus resistente à } \\
\text { vancomicina -VRE-(2). }\end{array}$ \\
\hline $\begin{array}{l}\text { Geriatric Research } \\
\text { Education and } \\
\text { Clinical Center - } \\
\text { (EUA) }\end{array}$ & 7 & $\begin{array}{l}\text { Equipamentos hospitalares (3); } \\
\text { tela de computador (2); } \\
\text { superfícies - ambiente } \\
\text { hospitalar (1); superfícies - } \\
\text { ambiente extra hospitalar (1) }\end{array}$ & $\begin{array}{l}\text { Staphylococcus aureus resistente à meticilina } \\
\text { (MRSA) e esporos de Clostridium difficile (3); } \\
\text { Candida auris e MRSA (1); Escherichia coli e } \\
\text { e esporos de Clostridium difficile (1); } \\
\text { Staphylococcus aureus resistente à meticilina } \\
\text { (MRSA) (1); Esporos de Clostridium difficile, } \\
\text { Staphylococcus aureus resistente à meticilina } \\
\text { (MRSA) e Enterococcus resistente à } \\
\text { vancomicina -VRE-(1). }\end{array}$ \\
\hline $\begin{array}{l}\text { Centre National de } \\
\text { la Recherche } \\
\text { Scientifique } \\
\text { (França) }\end{array}$ & 7 & $\begin{array}{l}\text { Ar(4); superfícies - ambiente } \\
\text { extra hospitala (1); tratamento } \\
\text { de água (1); equipamentos } \\
\text { hospitalares(1) }\end{array}$ & $\begin{array}{l}\text { Algas (1); Salmonella typhimurium (1); Cepas } \\
\text { bacterianas gram-positivas e gram-negativas } \\
\text { (1); Não se plicou em microorganismos (1); } \\
\text { Escherichia coli (1); Aspergillus fumigatus (1); } \\
\text { Escherichia coli - aerossol bacteriano (1) }\end{array}$ \\
\hline $\begin{array}{l}\text { Consejo Nacional } \\
\text { De Investigaciones } \\
\text { Cientificas } \quad \text { y } \\
\text { Tecnicas }\end{array}$ & 6 & $\begin{array}{l}\text { Alimentos } \quad \text { sólidos } \\
\text { diversificados (3); frutas (2); } \\
\text { bebidas (1) }\end{array}$ & $\begin{array}{l}\text { Eruca vesicaria subsp. Sativa (1); Escherichia } \\
\text { coli (1); Botrytis cinerea (1); B. cinerea e } \\
\text { Monilia fructigena (1); Escherichia coli }+ \\
\text { Salmonella Enteritidis }+ \text { Saccharomyces }\end{array}$ \\
\hline
\end{tabular}




\begin{tabular}{|c|c|c|c|}
\hline (Argentina) & & & cerevisiae (1); não especificado (1) \\
\hline $\begin{array}{l}\text { United States } \\
\text { Department of } \\
\text { Agriculture (EUA) }\end{array}$ & 6 & $\begin{array}{l}\text { Alimentos sólidos } \\
\text { diversificados (2); plantas) (1); } \\
\text { frutas(1); placas com meios de } \\
\text { cultura(1); não esecificado(1) }\end{array}$ & $\begin{array}{l}\text { Tetranychus urticae Koch(1); Escherichia } \\
\text { coli(1); Salmonella (1) Yersinia pestis(1); } \\
\text { Vírus da imunodeficiência humana (HIV), } \\
\text { bacteriófago M13 e citomegalovírus murino } \\
(\mathrm{MCMV})(1) \text {; Penicillium expansum (1). }\end{array}$ \\
\hline $\begin{array}{l}\text { Universidad de } \\
\text { Cadiz - } \\
\text { (Espanha) }\end{array}$ & 5 & $\begin{array}{l}\text { Tratamento de água de lastro } \\
\text { (3); tratamento de água(1); } \\
\text { remoção de algas marinhas } \\
\text { encontradas em água (1) }\end{array}$ & $\begin{array}{l}\text { Bactérias(1); Klebsiella pneumoniae e } \\
\text { Escherichia coli (1); Enterococcus faecalis(1); } \\
\text { Tisochrysis lutea(1); microrganismo não } \\
\text { especificado(1) }\end{array}$ \\
\hline $\begin{array}{l}\text { University North } \\
\text { Carolina Hospital - } \\
\text { (EUA) }\end{array}$ & 5 & $\begin{array}{l}\text { Não } \quad \text { especificado(2); } \\
\text { superfícies(2) ambiente extra- } \\
\text { hospitalar(1); }\end{array}$ & $\begin{array}{l}\text { Esporos de MRSA e Clostridium difficille(1); } \\
\text { microrganismos multirresistentes e Clostridium } \\
\text { difficille(1); MRSA +Enterobactéria Resistente } \\
\text { à Carbapenêmicos(ERC) } \\
\text { não especificados(1) }\end{array}$ \\
\hline $\begin{array}{l}\text { University of } \\
\text { Udine - (Itália) }\end{array}$ & 5 & $\begin{array}{l}\text { Frutas(3); alimentos sólidos } \\
\text { diversidifcados(1); tratamento } \\
\text { de água usada para enxague de } \\
\text { produtos(1) }\end{array}$ & $\begin{array}{l}\text { Não se aplica(2); Pseudomonas } \operatorname{spp}(1) \text {; } \\
\text { Leveduras e bactérias(1); Salmonella enterica, } \\
\text { Listeria monocytogenes e Escherichia coli(1) }\end{array}$ \\
\hline
\end{tabular}

Fonte: Autores, a partir de dados coletados na Web of Science.

Em relação à categoria das organizações que possuem o maior número de publicações sobre o assunto (Quadro 1), foram identificadas nove universidades e quatro centros de pesquisa. As organizações Case Western Reserve University e Louis Stokes Cleveland Veterans Affairs Medical Center desenvolveram uma parceria que resultou nas publicações 8 artigos sobre o assunto. Em seguida, aparece a Geriatric Research Education and Clinical Center, com sete artigos que também foram publicados em coautoria com as duas organizações citadas anteriormente. Na sequência temos as instituições: Centre National de la Recherche Scientifique (sete); Consejo Nacional De Investigaciones Cientificas y Tecnicas (sete); United States Department of Agriculture (seis); Universidad de Cadiz (cinco); University North Carolina Hospita (cinco); e University of Udine (cinco). Em relação ao país das organizações que mais publicaram sobre o assunto (Quadro 1), cinco delas estão situadas nos EUA, e as outras quatro organizações estão localizadas na França, Argentina, Espanha e Itália.

O Quadro 2 sintetiza as informações relacionadas às aplicações da radiação Ultravioleta-C identificadas nos 230 artigos recuperados. Verifica-se a predominância do uso desta tecnologia em alimentos 74(32\%), seguido do uso de raios UVC em água 53(23\%); em laboratórios 41 (18\%); em ambiente hospitalar 24(11\%); no ar nove (4\%) e em ambiente extrahospitalar oito (3\%). Foram observadas aplicações diversas, tendo sido enquadradas na categoria 'outros' 19(8\%). Também foram localizadas publicações que não especificaram as aplicações da radiação UV-C dois (1\%). 
Quadro 2. Aplicações da tecnologia de radiação ultravioleta-c (2014-2018). Rio de Janeiro, RJ, Brasil, 2020.

\begin{tabular}{|c|c|c|c|}
\hline $\begin{array}{l}\text { Aplicação Geral da } \\
\text { Tecnologia }\end{array}$ & Registros & $\%$ & Especificações \\
\hline Alimento & 74 & 32 & $\begin{array}{c}\text { Frutas (25); carnes e ovos (14); verduras (04); bebidas (15); alimentos sólidos } \\
\text { diversificados (16). }\end{array}$ \\
\hline Tratamento de água & 53 & 23 & $\begin{array}{l}\text { Tratamento de água de lastro (3); tratamento de água usada para enxague de } \\
\text { produtos e utensílios (2); remoção de algas marinhas encontradas em água } \\
\text { (5); esterilização de água por meio de materiais fotocrômicos (1); tratamento } \\
\text { de água para consumo e/ou residual (42) }\end{array}$ \\
\hline Laboratório & 41 & 18 & $\begin{array}{l}\text { Caldo com meio nutritivo (4), placas com meios de cultura (10), Ácido } \\
\text { difenilarsínico (DPAA) (1), Ácidos graxos de membranas (1), biofilmes (2), } \\
\text { caldo com meio nutritivo (4), Ciprofloxacina, sarafloxacina e norfloxacina (1), } \\
\text { DNA (2), Ferida cirúrgica superficial de rato (1), Fósforos que emitem } \\
\text { luminescência(1), nanocarreadores de oxigênio (1), Nanofios de núcleo-casca } \\
\text { (1), nanofios(1), Nanopartículas de microrganismos (1), plasma(1), ringer } \\
\text { lactato (1), sola de sapato(1), solução tampão (1), suco de uva clara (1), vacina } \\
\text { suína (1), superfícies de vidro (1), sulfametoxazol (1), laboratório (2). }\end{array}$ \\
\hline $\begin{array}{l}\text { Ambiente } \\
\text { Hospitalar }\end{array}$ & 24 & 11 & $\begin{array}{l}\text { Equipamentos hospitalares (3); filtro EPA (2); membranas de estetoscópio (2); } \\
\text { acomodações hospitalares (2); teclado de computador (2); instrumentos } \\
\text { cirúrgicos (1); sondas endovaginais (1); tela de computador (1), Terapia } \\
\text { Intensiva Cardiológica-taxas de pneumonia (1); Superfícies (9) }\end{array}$ \\
\hline $\mathrm{Ar}$ & 9 & 4 & Partículas no ar(9) \\
\hline $\begin{array}{l}\text { Ambiente extra- } \\
\text { hospitalar }\end{array}$ & 8 & 3 & $\begin{array}{l}\text { Banheiro público (2), Centro de radiologia (1), ambiente extra-hospitalar(3), } \\
\text { superfícies de ambiente (2) }\end{array}$ \\
\hline Outros & 19 & 8 & $\begin{array}{l}\text { Plantas (05); Fósforo (02); Biofilme }(01) \text {; Dosímetro }(01) \text {; } \\
\text { Fotoluminescência }(01) \text {; Gás }(01) \text {; Hipoclorito de sódio }(01) \text {; Materiais } \\
\text { odontológicos (01); Nanomateriais (01); Painel }(01) \text {; Tubo }(01) \text {; Vara } \\
\text { germicida (01) e; Centro de Radiologia (01); Tratamento de efluente de } \\
\text { biodiesel (1). }\end{array}$ \\
\hline Não especificado & 2 & 1 & Não há \\
\hline Total & 230 & 100 & \\
\hline
\end{tabular}

Fonte: Autores, a partir de dados coletados na Web of Science.

O levantamento dos microrganismos combatidos (Quadro 3) apontou a predominância de bactérias (53\%) nos testes com a radiação UV-C. 
Quadro 3. Microrganismos alvo da tecnologia de raios UV-C. Rio de Janeiro, RJ, Brasil, 2020.

\begin{tabular}{|c|c|c|c|}
\hline $\begin{array}{c}\text { Tipos de } \\
\text { microrganismos }\end{array}$ & $\begin{array}{l}\text { Número } \\
\text { de artigos }\end{array}$ & $\%$ & Especificações \\
\hline Bactérias & 122 & 53 & 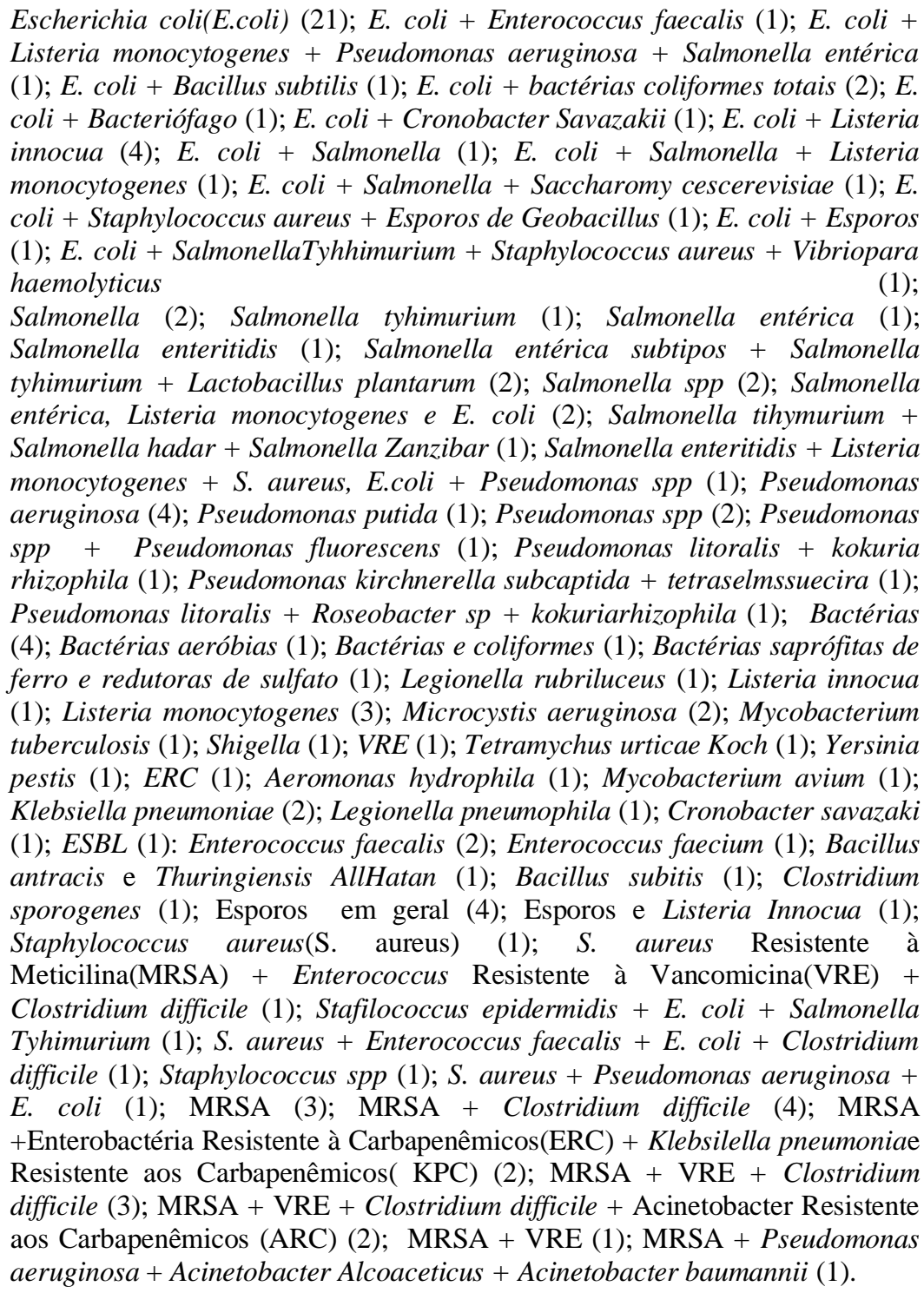 \\
\hline Bactérias e vírus & 2 & 1 & $\begin{array}{l}\text { ClamidiaTrachomatis, HPV (1); E. coli }+ \text { Vírus substitutos de } \\
\text { bacteriófagos(1); }\end{array}$ \\
\hline Bactérias e fungos & 6 & 3 & $\begin{array}{l}\text { Enterobactérias e cargas aeróbicas mesofílicas, mofo e leveduras (1); Culturas } \\
\text { de bactérias e leveduras coliformes (1); MRSA + Candida sp (1); Bactérias e } \\
\text { fungos (3); }\end{array}$ \\
\hline Algas & 3 & 1 & Não especificadas(2); Tisochrysis lutea(1). \\
\hline Fungos & 9 & 3 & $\begin{array}{l}\text { Cladosporim cladosporióides (1); Batrytis cinérea (1); Fungos (2); Penicillium } \\
\text { expansum }(1) \text {; Fungos + Lactobacillus + Leveduras (2); Aspergillus niger (1); } \\
\text { Aspergillus fumigatus (1). }\end{array}$ \\
\hline Vírus & 4 & 2 & $\begin{array}{l}\text { Vírus (1); Vírus da Hepatite A + Novovírus (1); Vírus da Imunodeficiência } \\
\text { Humana(HIV), Bacteriófagos, Citomegalovírus murino(MCMV) } \\
\text { Calcivírus felino(FCV) (1) }\end{array}$ \\
\hline
\end{tabular}




\begin{tabular}{|cccl|}
\hline Não especificado & 55 & 24 & Não especificado \\
\hline Não se aplica & 29 & 13 & Não foi aplicado em microrganismos \\
\hline Total & 230 & 100 & \\
\hline
\end{tabular}

Fonte: Autores, a partir de dados coletados na Web of Science (2019).

Pelo estudo bibliométrico, pode-se identificar que a produção científica nesta área está em crescimento, os achados indicam que os estudos, em sua maioria, foram pesquisas quali-quantitativas, publicadas nos periódicos desenvolvidas no continente americano, que muito tem se mobilizado na realização das pesquisas em ambiente hospitalar.

Percebe-se que os dados apontam que a maior parte das pesquisas são referentes à usabilidade e aplicabilidade da radiação ultravioleta-c nos alimentos, seguido da água, porém haja vista, as organizações que mais publicaram sobre o tema realizaram estudos no ambiente hospitalar.

\subsection{A usabilidade da radiação ultravioleta-c no ambiente hospitalar}

Essa categoria foi composta de 24 artigos, os quais apontam exemplos de uso da tecnologia em saúde e experiências vivenciadas nos diversos ambientes hospitalares, com aplicabilidade direta em equipamentos médicos, componentes de computadores, artigos hospitalares e superfícies de ambientes diversificados, demonstrando o quanto são indispensáveis. Cada vez mais os profissionais de saúde estão trabalhando em um ambiente de alta tecnologia e devem usar recursos inovadores para tornar excelente o atendimento ao paciente.

Outro ponto que merece ser destacado nos artigos encontrados na pesquisa sobre o ambiente hospitalar seria a aplicabilidade de equipamento para desinfecção de ambiente hospitalar contínuo, esse mecanismo reduz consideravelmente as bactérias no ambiente, diminuindo o número de infecções relacionadas a assistência à saúde, os custos hospitalares e a morbidade (Cadnum, et al., 2018).

Corroborando o fato da utilização da tecnologia de desinfecção, países como a China e Koréia estão utilizando tecnologias à base de radiação ultravioleta-c para desinfecção de ambientes com pacientes internados e com infecção pelo COVID-19, evidenciando que o emprego da tecnologia para o enfrentamento à pandemia do novo Coronavírus.

No cenário nacional este tema ainda é um desafio a ser mais explorado por profissionais de saúde como um todo e a realização desta pesquisa permitiu, também avaliar a escassez de estudos no cenário hospitalar brasileiro.

\section{Conclusão}

Em razão de seus efeitos microbicidas, a radiação ultravioleta $-\mathrm{C}$ tem sido utilizada em diversas áreas, tais como ambientes hospitalares, indústria de alimentos, dentre outros. Tendo em vista o potencial germicida desta tecnologia em superfícies, em líquidos e no ar, considerou-se relevante identificar o panorama das publicações científicas sobre a utilização de raios UVC.

Observou-se o crescimento no número de artigos científicos, tendo o ano de 2018 apresentado o maior número de publicações, o que pode ser um indicativo de aumento de interesse pelo tema. 
A análise da produtividade por país assinalou os EUA como o detentor do maior número de publicações, seguido da Espanha e da China. Identificou-se a predominância de artigos publicados em inglês, o que pode ser considerado como um esforço para ampliar a visibilidade das pesquisas sobre esse conteúdo temático.

O mapeamento da distribuição dos artigos por periódicos revelou que as revistas que mais publicaram sobre o assunto no período delimitado, estão relacionadas às áreas de Ciência e Tecnologia de Alimentos, Ciências Ambientais, Biologia/Microbiologia, Biologia/Biotecnologia, Doenças infecciosas, Bioquímica e Biologia Molecular.

A averiguação dos ambientes de aplicação dos raios ultravioleta-c, revelou a utilização desta tecnologia em alimentos, em água, em laboratórios, em ambiente hospitalar, no ar, em ambiente extra-hospitalar, dentre outros. Neste sentido, observouse a predominância de uso dos raios UVC em alimentos, o que assinala a relevância deste recurso tecnológico como uma das medidas de fortalecimento da segurança alimentar.

Por meio do levantamento dos microrganismos alvo, constatou-se a predominância do uso desta tecnologia no combate a bactérias. Neste contexto, aponta-se a necessidade de se ampliar as pesquisas que tenham por objetivo combater por meios dos raios UVC, outros tipos microrganismos patogênicos.

Conclui-se que mais pesquisas no ambiente hospitalar precisam ser realizadas pela comunidade científica no Brasil e mundialmente, como um complemento à limpeza padrão na redução de patógenos nosocomiais em instituições de saúde e são necessários para melhor esclarecer a questão da prática de cuidados de saúde baseados em evidências.

Trata-se de uma tecnologia com alto potencial de contribuição no enfrentamento à pandemia da Covid-19, doença causada pelo novo Coronavírus (SARS-CoV2), visto que a radiação ultravioleta-c foi apontada como um mecanismo de combate a diversos microrganismos, dentre eles os vírus.

Estudos voltados para tecnologias de desinfecção à base de radiação ultravioleta-c demandam conhecimentos multi e interdisciplinares. Com a Pandemia pelo SARS-CoV2 o interesse por tecnologias de desinfecção em ambientes hospitalares à base de radiação ultravioleta-c aumentará significativamente ao longo do tempo.

\section{Referências}

Anderson, M., Weber, L., Chen, L. F., Schwab, J. C., \& Sexton, D. J. (2018). Effectiveness of targeted enhanced terminal room disinfection on hospital-wide acquisition and infection with multidrug-resistant organisms and Clostridium difficile: a secondary analysis of a multicentre cluster randomised controlled trial with crossove. Lancet Infectious Diseases, 845-853.

Araque, L., Rodoni, L., Darré, M., Ortiz, C., Civello, P., \& Vicente, A. (2018). Cyclic low dose UV-C treatments retain strawberry fruit quality more effectively than conventional pre-storage single high fluence applications. LWT - Food Science and Technology, 92, $304-311$.

Cadnum, J., Shaikh, A., Piedrahita, C., Jencson, Larkin, E., Ghannoum, M., \& Donskey, C. J. (2018). Relative Resistance of the Emerging Fungal Pathogen Candida auris and Other Candida Species to Killing by Ultraviolet Light. Infection Control and Hospital Epidemiology, 39(1), 94-96.

Choudhary, R., \& Bandla, S. (2012). Pasteurização ultravioleta para indústria de alimentos. Revista Internacional de Ciência de Alimentos e Engenharia de Nutrição, 2(1), 12-15.

Clímaco, W., Melo, E. D. P. V., Saldanha, M., Pinto, M., Fernandes, L., \& Lara, L. (2018). Microbiologia e qualidade de casca de ovos incubáveis submetidos a diferentes procedimentos de desinfecção. Pesquisa Agropecuária Brasileira, 53(10).

Coordenação de Controle de Infecção. (1994). Processamento de Artigos e Superfícies em Estabelecimentos de Saúde. Brasília: Ministério da Saúde do Brasil.

Correa, T., Blanco, K., Inada, N., Hortenci., M., Costa, A., Silva, E., \& Bagnato, V. (2017). Manual Operated Ultraviolet Surface Decontamination for Healthcare Environments. Photomedicine and Laser Surgery, 666-671.

Couto, J. F. (2019). Testagem de uma tecnologia de desinfecção à base de radiação ultravioleta-c no ambiente cirúrgico: Uma metodologia para enfermeiros na perspectiva de Florence Nightingale. Rio de Janeiro: Programa de Pós-Graduação em Enfermagem e Biociências da Universidade Federal do Estado do Rio de Janeiro.

Ethington, T., Newsome, S., Waugh, J., \& Lee, L. (2018). Cleaning the air with ultraviolet germicidal irradiation lessened contact infections in a long-term acute care hospital. American Journal of Infection Control, 46(5), 482-486.

Gerchman, Y., HadasMamane, Friedman, N., \& Mandelboim, M. (2020). UV-LED disinfection of Coronavirus: Wavelength effect. Journal of Photochemistry and Photobiology B: Biology, 212. 
Gunter-Ward, D., Patras, A., Bhullar, M., Kilonzo-Nthenge, A., Pokharel, B., \& Sasges, M. (2018). Efficacy of ultraviolet (UV-C) light in reducing foodborne pathogens and model viruses in skim milk. Journal of Food Processing and Preservation, 42(2).

Holck, A., Liland, K., M, C., \& E, H. (2018). Reductions of Listeria monocytogenes on cold-smoked and raw salmon fillets by UV-C and pulsed UV light. 110 .

Hull, N., \& Linden, K. (2018). Synergy of MS2 disinfection by sequential exposure to tailored UV wavelengths. Water Research, $292-300$.

Imaizumi, T., Yamauchi, M., Sekiya, M., Shimonishi, Y., \& Tanaka, F. (2018). Responses of phytonutrients and tissue condition in persimmon and cucumber to postharvest UV-C irradiation. Postharvest Biology and Technology, 145, 33-40.

Jeon, M., \& Ha, J. (2018). Efficacy of UV-A; UV-B; and UV-C irradiation on inactivation of foodborne pathogens in different neutralizing buffer solutions. Lwt-Food Science and Technology, 98, 591-597.

Kviatkovski, I., Mamane, H., Lakretz, A., Sherman, I., Beno-Moualem, D., \& Minz, D. (2018). Resistance of a multiple-isolate marine culture to ultraviolet C irradiation: inactivation vs biofilm formation. Letters in Applied Microbiology, 67(3), 278-284.

Lai, A., Nunayon, S., Tan, T., \& Li, W. (2018). A pilot study on the disinfection efficacy of localized UV on the flushing generated spread of pathogens. Journal of Hazardous Materials, 358, 389-396.

Liu, C., Huang, Y., \& Chen , H. (2015). Inactivation of Escherichia Coli O157:H7 and Salmonella Enterica on Blueberries in Water Using Ultraviolet Light. Journal of Food Science, 80.

Lopez, N., Plaza, S., Afkhami, A., Marco, P., Giménez, J., \& Espulgas, S. (2017). Treatment of Diphenhydramine with different AOPs including photo-Fenton at circumneutral pH. Chemical Engineering Journal, 318, 112-120.

Mcleod, A., Liland, K., Haugen, J., Sorheim, O., Myhrer, K. S., \& Holck, A. L. (2018). Chicken fillets subjected to UV-C and pulsed UV light: Reduction of pathogenic and spoilage bacteria; and changes in sensory quality. Journal of Food Safety, 38(1).

Milonova, S., Brandston, H., Rudnick, S., Ngai, P., Simonson, K., Rahman, S., \& Nardell, E. (2017). A design for a more efficient; upper room germicidal ultraviolet air disinfection luminaire. Lighting Research \& Technology, 49(6), 788-799.

Moreno-Andres, J., Acevedo-Merino, A., \& Nebot, E. (2018). Study of marine bacteria inactivation by photochemical processes: disinfection kinetics and growth modeling after treatment. Environmental Science and Pollution Research, 25(28).

Murray, K., Moyer, P., Wu, F., Goyette, J., \& Warriner, K. (2018). Inactivation of Listeria monocytogenes on and within Apples Destined for Caramel Apple Production by Using Sequential Forced Air Ozone Gas Followed by a Continuous Advanced Oxidative Process Treatment. Journal of Food Protection, 81(3), $357-364$.

Nocker, A., Shah, M., Dannenmann, B., Schulze-Osthoff, K., Wingender, J., \& Probst, A. (2018). Assessment of UV-C-induced water disinfection by differential PCR-based quantification of bacterial DNA damage. Journal of Microbiological Methods, 149, 89-95.

Pavia, M., Simpser, E., Becker, M., Mainquist, K., \& Velez, K. (2018). The effect of ultraviolet-C technology on viral infection incidence in a pediatric longterm care facility. American Journal of Infection Control.

Pedros-Garrido, S., Condon-Abanto, S., Clemente, I., Beltran, J., Lyng, Bolton, \& Whyte. (2018). Efficacy of ultraviolet light (UV-C) and pulsed light (PL) for the microbiological decontamination of raw salmon (Salmo solar) and food contact surface materials. Innovative Food Science \& Emerging Technologies, $50,124-131$.

Pereira, A. S., Shitsuka, D. M., Parreira, F. J., \& Shitsuka, R. (2018). Metodologia da pesquisa científica. UFSM.

Pfendler, S., Einhorn, O., Karimi, B., Bousta, F., Cailhol, D., Alaoui-Sosse, L., \& Aleya, L. (2017). UV-C as an efficient means to combat biofilm formation in show caves: evidence from the La Glaciere Cave (France) and laboratory experiments. Environmental Science and Pollution Research, 24(31).

Ponnaiya, B., Buonanno, M., Welch, D., Shuryak, I., Randers-Pehrson, G., \& Brenner, D. J. (2018). Far-UVC light prevents MRSA infection of superficial wounds in vivo. Plos One, 13(2).

Possas, A., Valero, A., Garcia-Gimeno, R., Perez-Rodriguez, F., \& Souza, P. (2018). Influence of temperature on the inactivation kinetics of Salmonella Enteritidis by the application of UV-C technology in soymilk. Food Control, 132-139.

Rashid, T., Poblete, K., Amadio, J., Hasan, I., Begum, K., Alam, M., \& Garey, K. (2018). Evaluation of a shoe sole UVC device to reduce pathogen colonization on floors, surfaces and patients. Journal of Hospital Infection, 98(1), 96-101.

Ribeiro, A., Sures, Sures, B., \& Schmidt, T. (2018). Ecotoxicity of the two veterinarian antibiotics ceftiofur and cefapirin before and after phototransformation. Science of the Total Environment, 619, 866-873.

Rizzo, L., Lofrano, G., Gago, C., Bredneva, T., Iannece, P., Pazos, M., \& Carotenuto, M. (2018). Antibiotic contaminated water treated by photo driven advanced oxidation processes: Ultraviolet/H2O2 vs ultraviolet/peracetic acid. Journal of Cleaner Production, 205, 67-75.

Rodriguez-Chueca, J., Laski, E., Garcia-Canibano, C., Vidales, M. D., Encinas, Á., Kuch, B., \& Marugán, J. (2018). Micropollutants removal by full-scale UV-C/sulfate radical based Advanced Oxidation Processes. Science of the Total Environment, 630, 1216-1225.

Sachs, D., Medeiros, R., \& Rodrigues, R. (2015). Tecnologia de Sistemas Ultravioleta (UV) no combate às bactérias resistentes em ambientes hospitalares. Diagrate. Fonte: diagrarte.com.br. 